\title{
Investigation of Nano Selenium Influence on Productivity and Hematological Exponents of Broiler Chickens
}

\author{
Konkov, A. A. ${ }^{1}$, Ampleeva, L.V. ${ }^{1}$, Polishchuk, S. D. ${ }^{1} \&$ Churilov, G. I. ${ }^{2}$ \\ ${ }^{1}$ Faculty of Chemistry, Agrotechnological University, Ryazan, Russia \\ ${ }^{2}$ Faculty of Organic Chemistry, Medical University, Ryazan, Russia \\ Correspondence: Churilov, G. I., Faculty of Organic Chemistry, Medical University, Ryazan, 390026, Russia. Tel: \\ 7-891-0901-3298. E-mail: genchurilov@yandex.ru
}

Received: April 22, 2015

doi:10.5539/mas.v9n13p36
Accepted: June 29, 2015

URL: http://dx.doi.org/10.5539/mas.v9n13p36

\begin{abstract}
They have shown the influence of nano selenium water solution on intensification of growth and broiler chickens' blood exponents change. Chickens' metabolism modification with nano selenium causes the changes of blood biochemical exponents depending on nano selenium concentration. They have used nano selenium at concentration of $0.1,0.01$ and $0.001 \mathrm{mgr} / \mathrm{kg}$ of live weight a day. Independent of the concentration one can see the increase of blood platelets and chickens' live weight and the decrease of the used fodder in all groups.
\end{abstract}

Keywords: nano selenium, broiler chickens, growth, development, hemopoiesis, proteins, carbohydrates, lipids

\section{Introduction}

Intensification of meat poultry breeding is caused by high need in cheap and still qualitative meat products. In connection with this the development of broiler industry towards dietary properties improvement and broiler chickens' meat food value plays an important role. The success of modern poultry breeding is possible only under definite circumstances like full fodder value concerning all nutritional and mineral substances and epizootic well-being of the place and farm. To guarantee preventive measures against metabolic disorder, microelementosis and beriberi it is necessary to use fodder additives, to which one attribute metals and non-metals nano-dimensioned particles having high biological availability, safety and cheapness. We have studied selenium effect, one of the most important micro-elements for animals and human beings. The inorganic selenate and selenite predominate in water while organic selenium junctions (selenomethionine, selenocysteine) are the basic kinds of selenium in grain and vegetable crops. We have got the experiment with 7 types of wild waterfowl to investigate selenium toxicity and influence on oxidative stress. The lab investigations mainly with organic selenium have shown the oxidative stress changes at different concentrations of selenomethionine and made it possible to determine the factors of toxicosis such as depletion, feather loss abnormality and histopathological affection. The authors have shown with mice the lower toxicity of nano selenium sized 5-200 $\mathrm{nm}$ as compared with inorganic or organic selenium as well as with selenium deficit its toxicity goes down resulting from the increase of selenium-containing proteins synthesis having the fundamental value for oxidation-reduction homeostasis. Selenium is a bio-corrector of the highest rank. Together with zinc, calcium and potassium it is a part of more than 200 hormones and ferments of the organism regulating the work of all organs and systems.

The aim of the investigation is studying the influence of selenium nano-particles suspension at different concentration on meat productivity and hematological indexes of broiler chickens.

\section{Materials and Methodology}

We have investigated selenium colloidal solutions got at the Institute of Metallurgy and Material Engineering Named after A.A. Baykov, RAS where they had discovered the method to prepare colloidal solutions of different chemical elements under the influence of powerful laser radiation. The method makes it possible to get water colloidal solutions of water-insoluble elemental selenium steadily. Selenium concentration in water determined by the method of nuclear-emission spectrometry with induction plasma (NES with IP) has been $9 \mathrm{mgr} / \mathrm{l}$.

We conducted the investigations in 2013 at poultry farm JSC "Ryazan Broiler", Ryazan district, Ryazan oblast. We were having experiments with broiler chickens of cross ROSS-308 during 37 days. To do that we formed 4 
groups of chickens on the principle of pairs-analogues taking into account the age, live weight and development level. The control group has got the basic diet. The $1^{\text {st }}$ experiment group got nano selenium in a dose of 0.1 $\mathrm{ugr} / \mathrm{kg}$ of live weight a day. The $2^{\text {nd }}$ experiment group got nano selenium in a dose of $0.01 \mathrm{ugr} / \mathrm{kg}$ of live weight a day and the $3 \mathrm{~d}$ experiment group got $0.001 \mathrm{ugr} / \mathrm{kg}$ of live weight a day. The chickens got the drug from the age of 14 days. We have had control tests of broiler chickens' clinical state with the help of everyday examination and periodical blood tests (every 10 days). We have determined the hematological indexes with the help of common methods and BioChem SA analyzer. The feeding and housing conditions have been the same. The experiment groups have got the fodder additive in the form of selenium nano-particles suspension together with water as a single dose for 20 days. So we didn't give water to the birds for an hour before giving the additive in order to activate its use.

\subsection{Statistical Analysis}

We have analyzed every parameter deviation. We have used Microsoft Excel for statistical processing.

\section{Investigation Results}

The deviation of the organism functional status in a case of using fodder additives and other substances first influences the hematological indexes. That is why we have evaluated the bird's clinical state taking into account the clinical blood analysis.

\subsection{Influence of Selenium Nano-Particles Suspension on Blood Morphological Indexes}

As it is seen from Table 1 all blood indexes do not correspond the physiological norm.

Table 1. Morphological Indexes of Broiler Chickens before the Experiment

\begin{tabular}{lllll}
\hline Index & \multicolumn{3}{l}{ Broiler Chickens Groups } \\
\cline { 2 - 5 } & Control & Experiment 1 & Experiment 2 & Experiment 3 \\
\hline Leucocytes $10^{9} / 1$ & $17.32 \pm 3.53$ & $16.38 \pm 1.63^{* *}$ & $17.19 \pm 1.94^{* * *}$ & $16.69 \pm 0.35^{*}$ \\
Erythrocytes $10^{12} / 1$ & $1.37 \pm 0.09^{*}$ & $1.46 \pm 0.09^{*}$ & $1.42 \pm 0.03^{*}$ & $1.46 \pm 0.05^{*}$ \\
Hemoglobin gr/1 & $104.50 \pm 0.50^{*}$ & $103.65 \pm 1.35^{* *}$ & $101.35 \pm 1.05^{*}$ & $106.05 \pm 1.65^{* *}$ \\
Hematocrit \% & $14.80 \pm 0.77^{*}$ & $14.90 \pm 0.40^{*}$ & $14.31 \pm 1.00^{* *}$ & $14.72 \pm 0.47^{*}$ \\
Platelets $\mathrm{mln} / 1$ & $52.50 \pm 2.50$ & $50.35 \pm 0.65^{*}$ & $51.50 \pm 2.30$ & $53.00 \pm 1.70$ \\
\hline
\end{tabular}

Note: $* \mathrm{P}<0.05 * * \mathrm{P}<0.01 * * * \mathrm{P}<0.001$.

So the average values of leucocytes, erythrocytes and hematocrit are 2 times lower, platelets are 0.8 times lower and hemoglobin is 1.1 times higher than the norm.

Table 2. Morphological Exponents of Broiler Chickens Blood after the Experiment

\begin{tabular}{ccccc}
\hline Exponent & Control & Experiment 1 & Experiment 2 & Experiment 3 \\
\hline Leucocytes $10^{9} / 1$ & $27.41 \pm 2.05$ & $21.95 \pm 0.13 *$ & $34.78 \pm 1.13^{* * *}$ & $30.90 \pm 1.22 * * *$ \\
Erythrocytes $10^{12} / 1$ & $2.13 \pm 0.01 *$ & $1.93 \pm 0.23 * *$ & $2.16 \pm 0.01 *$ & $2.38 \pm 0.16^{*}$ \\
Hemoglobin gr/1 & $145.50 \pm 7.50$ & $132.50 \pm 11.50$ & $156.00 \pm 1.00^{* *}$ & $161.67 \pm 5.84$ \\
Hematocrit \% & $22.60 \pm 0.17 * * *$ & $20.51 \pm 2.54$ & $22.58 \pm 0.27 *$ & $24.50 \pm 1.56$ \\
Platelets $\mathrm{mln} / 1$ & $36.42 \pm 2.05$ & $51.34 \pm 2.21$ & $51.84 \pm 0.55^{* *}$ & $55.10 \pm 0.32 *$ \\
\hline
\end{tabular}

Note: $* \mathrm{P}<0.05 * * \mathrm{P}<0.01 * * * \mathrm{P}<0.001$.

\subsubsection{Hematological Exponents Comparative Analysis}

The oxidation-reduction processes in the organism characterize to some extent the numbers of erythrocytes and hemoglobin concentration.

Hemoglobin transports oxygen and carbon dioxide and shows the buffer properties. It can connect some toxic substances as well. It is seen from Table 2 that the chickens that have got selenium nano-particles suspension have had different morphological blood indexes as compared with those from the control group. One can 
mention the $7 \%$ hemoglobin decrease in the $1^{\text {st }}$ experiment group and the $7 \%$ and $11 \%$ hemoglobin increase in the $2^{\text {nd }}$ and $3 \mathrm{~d}$ experiment groups correspondingly.

The main task of erythrocytes is to provide oxygen for tissues and transfer of carbon dioxide back from the tissues to lungs. The influence of selenium nano-particles suspension on erythrogenesis has had a sparing action in the $1^{\text {st }}$ group (9.4\% lower than the control) and a stimulating effect in the $2^{\text {nd }}$ and $3 \mathrm{~d}$ groups $(1.4 \%$ и $11.7 \%$ correspondingly).

Hematocrit allows estimating the degree of anemia manifestation that is an important index when evaluating the animal's clinical state. This index in the $1^{\text {st }}$ and $2^{\text {nd }}$ groups has been $9.2 \%$ and $0.1 \%$ lower as compared with that of the control and the same index in the $3 \mathrm{~d}$ group has been $8.4 \%$ higher.

Thus, adding nano selenium to the diet has stimulated the function of hematogenesis that has appeared in the increase of erythrocytes, hemoglobin and hematocrit. These data prove intensification of oxidation-reduction processes in the organism of broiler chickens.

The number of leucocytes in the blood of animals can vary in a wide range. During the experiment the number of leucocytes in the control and experiment groups has been within the norm. There has been the $27 \%$ and $13 \%$ increase of the leucocytes number in the $2^{\text {nd }}$ and $3 \mathrm{~d}$ groups correspondingly and the $19 \%$ decrease in the $1^{\text {st }}$ group as compared with that of the control.

The main function of platelets is participation in the process of hemostasis (a complex of reactions to stop the bleeding). Platelets take part in protecting organisms from alien agents. They can destroy some bacteria membrane. In a case with the vessels injure they protect the organism from an infection. One can see the platelets increase in a case with using the additive in all experiment groups by $40.96 \%, 42.33 \%$ and $51.29 \%$ correspondingly as compared with the control.

The broiler chickens healthy growth is accompanied with high activity of biochemical processes in organs and tissues. To evaluate the nano selenium influence on metabolic processes we have determined the level of some biochemical indexes of blood serum characterizing proteins, carbohydrates and lipids metabolism.

\subsection{Selenium Nano-Particles Suspension Influence on Metabolic Processes}

\subsubsection{Protein Metabolism}

Protein metabolism is central and top-priority as without proteins and amino acids there can not be any reproduction of cells basic structural components, tissues and organs, ferments and hormones synthesis and so on.

One can speak about protein metabolism judging by the change of crude protein and its fractions content in blood serum.

Crude protein is total concentration of albumen and globulins in blood serum. Crude protein participates in blood clotting; supports blood pH constancy; transports fats, bilirubin and steroid hormones to tissues and organs and is involved with immune reactions and other functions.

Table 3. Influence of Selenium Nano-Particles Suspension on Broiler Chickens Protein Metabolism

\begin{tabular}{|c|c|c|c|c|c|c|c|c|c|}
\hline \multirow[t]{2}{*}{ Group } & \multicolumn{3}{|c|}{ Crude protein, gr/l } & \multicolumn{3}{|c|}{ Albumen, gr/l } & \multicolumn{3}{|c|}{ Urea Nitrogen, gr/l } \\
\hline & Before & 10 days & 20 days & Before & 10 days & 20 days & Before 1 & 0 days & 20 days \\
\hline Control & $43.08 \pm$ & 45.1 & $51.87 \pm 6.04$ & $8.72 \pm$ & $7.09 \pm 0.55$ & 14.5 & $1.10 \pm$ & $0.66 \pm$ & \\
\hline & 3.32 & 3.05 & & 1.61 & & & $19^{*}$ & & \\
\hline Experi1 & 43.47 & 49.5 & & $8.56 \pm$ & $13.71 \pm 2$ & 14.73 & $1.05 \pm$ & & \\
\hline 1 & & 5.9 & & 1.53 & & & $0.09 *$ & $0.26^{*}$ & $0.12 *$ \\
\hline Experi & $44.52 \pm$ & 62.10 & $44.23 \pm 8.88$ & $8.37 \pm$ & $14.21 \pm 1.81 * *$ & $13.17 \pm 1.16$ & $1.11 \pm$ & $0.66 \pm$ & $0.86 \pm$ \\
\hline 2 & 4.1 & $4.16^{* * *}$ & & 1.76 & & & $0.15^{*}$ & $0.17^{*}$ & $0.07 *$ \\
\hline Experi1 & $41.18 \pm$ & $44.03 \pm$ & $49.53 \pm 5.61$ & $8.58 \pm$ & $11.11 \pm 2.26$ & $16.63 \pm 3.87$ & $1.14 \pm$ & $1.08 \pm$ & $0.92 \pm$ \\
\hline 3 & 3.76 & 0.98 & & 1.47 & & & $0.08 *$ & $0.07 *$ & $0.26^{*}$ \\
\hline
\end{tabular}

Note: $* \mathrm{P}<0.05 * * \mathrm{P}<0.01 * * * \mathrm{P}<0.001$.

Supervising the protein metabolism state of the broiler chickens during the whole period of growth has shown that in 10 days of the experiment the level of crude protein in the $1^{\text {st }}$ and $2^{\text {nd }}$ groups has been $9.5 \%$ and $37.4 \%$ higher and in the $3 \mathrm{~d}$ group $2.5 \%$ lower than that of the control. The indicator values in all experiment groups at 
the end of the period has been $7.2 \%, 14.7 \%$ and $4.5 \%$ lower than that of the control.

Albumins are the largest protein fraction in blood serum (53-66 \%). They synthesize in liver and support oncotic pressure in blood serum; transport different biologically active substances and can serve sources of endogenous amino acids in a case of their insufficient amount in the organism. Albumins connect cholesterol, bilirubin, calcium and many drug substances. They use the serum albumin test mainly to evaluate the liver protein-synthetic function and nutritional status.

The normal level of albumins in blood is a sign of good health and correct metabolism and vice versa the low one says about poor health. Albumen impoverishment in blood can happen in cases of malnutrition, gastro-intestinal tract diseases and digestion difficulties, chronic intoxications.

The change of correlation between some protein fractions in blood gives more information than crude protein.

So during the first decade of the experiment we have noticed the positive tendency in increasing this component in the experiment groups as compared with the control by $93.3 \%, 100.4 \%$ and $56.6 \%$ correspondingly. By the end of the period the positive tendency in albumen accumulation has remained in groups 1 and $3(1.5 \%$ and $14.6 \%$ higher than that of the control one) and has been $9.2 \%$ lower in the $2^{\text {nd }}$ group.

Urea nitrogen also reflects protein metabolism. Blood urea nitrogen is nitrogen found in final products of protein metabolism particularly urea. The urea originates in the liver from ammonia in the process of its deactivation and moves out through kidneys comprising 40-50\% of non-protein blood ammonia. Blood urea nitrogen lets estimate protein appearance and kidneys' excretory function.

The level of blood serum nitrogen in the experiment groups has been higher as compared with the control. So in the first decade this exponent in the $1^{\text {st }}$ and $3 \mathrm{~d}$ groups has been $34.8 \%$ and $63.6 \%$ correspondingly higher than the control. In the second decade this exponent has been $41.8 \%, 56.3 \%$ and $68.2 \%$ higher than the control.

\subsubsection{Carbohydrates Metabolism}

The basic role of carbohydrates and lipids in cell metabolism lies in the fact that their split into simpler compounds provides ATP synthesis, the energy necessary, first of all, for normal protein biosynthesis.

Blood glucose and amylase activity characterize carbohydrate metabolism intensity.

Blood glucose is a basic exponent reflecting carbohydrates metabolism. It is used for energetic and plastic purposes of all organs and tissues of animals. The glucose level in blood is in definite concentrations, characteristic for the type and age.

Amylase refers to glycosyl-hydrolases (digestive ferments) developed mainly in the pancreas, in small amounts in salivary glands and many other organs. It is responsible for splitting food complex carbohydrates components like starch and glycogen into simple carbohydrates (glucose). The hydrolysis starts in a mouth cavity then continues in a gastroenteric tract where its bigger part is synthesized by the pancreas. As starch molecules can not be absorbed in bowels due to its complex structure, the quality of food carbohydrates digestion depends on amylase activity. Kidneys remove amylase together with stale. Normally only a small amount of amylase circulates in the bloodstream (because of pancreas and salivary glands cells renovation) and goes to stale. In a case of a pancreas damage, as with pancreatitis, amylase gets into the bloodstream in large amounts and then into stale. Thus, $\alpha$-amylase activity helps us consider the pancreas state.

Table 4. Influence of Selenium Nano-Particles Suspension on Carbohydrate Metabolism of Broiler Chickens

\begin{tabular}{lcccccc}
\hline \multirow{2}{*}{ Group } & \multicolumn{3}{c}{ Glucose, $\mathrm{mmol} / 1$} & \multicolumn{3}{c}{ Amylase, items/l } \\
\cline { 2 - 7 } & Before & 10 days & 20 days & Before & 10 days & 20 days \\
\hline Control & $6.87 \pm 1.10$ & $4.45 \pm 0.70$ & $13.10 \pm 1.80$ & $209.83 \pm 20.54$ & $204.38 \pm 14.73$ & $164.73 \pm 34.35$ \\
Experiment 1 & $6.89 \pm 0.98 * *$ & $12.38 \pm 2.50 * * * 12.20 \pm 0.64 * 204.42 \pm 15.12$ & $191.13 \pm 18.33$ & $176.13 \pm 13.77$ \\
Experiment 2 & $6.54 \pm 1.23$ & $8.54 \pm 2.69$ & $15.33 \pm 1.89$ & $210.31 \pm 17.86$ & $189.18 \pm 15.21$ & $187.83 \pm 17.49$ \\
Experiment 3 & $6.67 \pm 1.05$ & $7.74 \pm 0.77 * * *$ & $12.70 \pm 0.21 *$ & $199.87 \pm 9.87$ & $153.83 \pm 20.04165 .03 \pm 10.70 * *$ \\
\hline te: $* \mathrm{P}<0.05 * * \mathrm{P}<0.01 * * * \mathrm{P}<0.001$. & & & &
\end{tabular}

As it is seen from table 4 before adding nano selenium to the diet the levels of glucose and amylase had inconsiderable oscillations in all groups. In the first decade of the experiment one could see positive dynamics in increasing glucose in all groups as compared with the control. So the 1st group had 178.2, the $2^{\text {nd }}$ one 91.9 and the $3 \mathrm{~d}$ one 73.9 correspondingly. At the end of the experiment the dynamics of glucose increase has remained in 
the $2^{\text {nd }}$ group where the exponent has been $17 \%$ higher than that of the control. The $1^{\text {st }}$ and $3 \mathrm{~d}$ groups have had exponents $6.8 \%$ and $3 \%$ lower than the control correspondingly.

The main function of amylase as a biologically active substance is splitting starch into simple oligosaccharides. The ferment activity compared with the control is not the same during the whole experiment. So the studied exponent in the first decade has been $6.5 \%, 7.5 \%$ and $24.8 \%$ lower than the control. In the second decade it has been $6.9 \%, 14 \%$ and $0.1 \%$ higher correspondingly.

\subsubsection{Lipids Metabolism}

We have studied lipids metabolism considering the following blood serum exponents: cholesterol, triglycerides and carotene.

Lipids have different functions in the organism, but first of all energetic, structural (form cell membranes) and storage.

The main sources of energy for cells are neutral fats or triglycerides, derivatives of glycerin and higher fatty acids. Triglycerides come into the organism with food, synthesize in fatty tissue, liver and bowels. Their level in blood depends, first of all, on the animal's age and type. They use triglycerides analysis while diagnosing atherosclerosis and many other diseases.

The most important component of fat metabolism is cholesterol used to form cells membranes and synthesis of steroid hormones, bile acids and vitamin D. Cholesterol forms in the liver (50-80\%), skin, adrenals and bowels walls. The rest part (20-50\%) comes with animal origin food (fatty meat, eggs, etc.). But the steroid surplus can lead to pathology (accumulation in vascular walls), so there is a necessity to produce dietetic meat with low cholesterol.

One can also attribute to lipoids carotene contained mainly in vegetable origin food and is a predecessor of vitamin A. Retinol (vitamin A) has important functions for animals. It provides the normal growth and development, participates in visual pigments creation, increase immunity, etc. Taking into account such various functions of vitamin A determining carotene and retinol is a compulsory element of the biochemical analysis.

Different animals have different ability to use fodder carotene. Chickens can assimilate only $0.6 \%$ of carotene from grass meal. But in comparison with other animals birds transform all carotene absorbed in the bowels into vitamin A. This process happens mainly in the liver with the help of special ferment called lipoxydase. This ferment activity is positively influenced by amino acids complete protein, anti-oxidants (selenium, tocopherol), zinc, glutathione, vitamin $B_{12}$ and cistein. It is presupposed that this vitamin has direct or indirect effect on protein metabolism, as in the case of its deficit there is a reduction of cells membranes penetration ability for some amino acids and as a result lowering activity of some ferments of protein metabolism. Therefore optimization of broiler chickens supply with carotene and vitamin A promotes high productivity and immunity stabilization.

Table 5. Influence of Selenium Nano-Particles Suspension on Lipids Metabolism of Broiler Chickens

\begin{tabular}{lccccccccc}
\hline \multirow{2}{*}{ Group } & \multicolumn{3}{c}{ Cholesterol, mmol/1 } & \multicolumn{3}{c}{ Triglycerides, $\mathrm{mmol} / 1$} & \multicolumn{3}{c}{ Carotene, $\mathrm{mmol} / 1$} \\
\cline { 2 - 10 } & Before & 10 days & 20 days & Before & 10 days & 20 days & Before & 10 days & 20 days \\
\hline Control & $2.62 \pm$ & $2.49 \pm$ & $2.85 \pm$ & $0.25 \pm 0.05$ & $0.28 \pm$ & $0.31 \pm 0.03$ & $0.40 \pm$ & $0.35 \pm$ & $0.40 \pm$ \\
& $0.14^{*}$ & $0.06^{*}$ & 0.46 & & $0.04^{* *}$ & & $0.01^{* * *}$ & $0.02^{*}$ & 0.05 \\
Experiment & $2.57 \pm$ & $2.93 \pm$ & $2.98 \pm$ & $0.26 \pm 0.02$ & $0.30 \pm$ & $0.35 \pm$ & $0.38 \pm 0.02$ & $0.39 \pm$ & $0.40 \pm$ \\
1 & 0.15 & $0.42^{*}$ & $0.33^{* *}$ & & 0.04 & $0.01^{* *}$ & & 0.01 & $0.01^{*}$ \\
Experiment & $2.60 \pm$ & $2.97 \pm$ & $3.06 \pm$ & $0.28 \pm$ & $0.32 \pm$ & $0.38 \pm$ & $0.40 \pm$ & $0.41 \pm$ & $0.43 \pm$ \\
2 & 0.11 & $0.22^{*}$ & $0.04^{*}$ & $0.02^{* * *}$ & $0.01^{* *}$ & $0.03^{* * *}$ & $0.01^{*}$ & $0.01^{* *}$ & 0.01 \\
Experiment & $2.59 \pm$ & $2.69 \pm$ & $2.64 \pm$ & $0.26 \pm 0.01$ & $0.30 \pm$ & $0.30 \pm$ & $0.37 \pm$ & $0.42 \pm$ & $0.42 \pm$ \\
3 & $0.07^{*}$ & 0.36 & $0.34^{* *}$ & & $0.01^{*}$ & $0.01^{*}$ & $0.01^{*}$ & $0.01^{*}$ & $0.01^{*}$ \\
\hline
\end{tabular}

Note: $* \mathrm{P}<0.05 * * \mathrm{P}<0.01 * * * \mathrm{P}<0.001$.

From table 5 one can see that blood serum cholesterol has had inconsiderable oscillations during the experiment. So in the middle of the experiment it has been $17.6 \%, 19.2 \%$ and $8 \%$ correspondingly higher than that of the control. By the end of the experiment the tendency in the $1^{\text {st }}$ and $2^{\text {nd }}$ groups has remained the same and cholesterol has been $4.5 \%$ and $7.3 \%$ higher than the control whereas the $3 \mathrm{~d}$ group has had $7.4 \%$ lower cholesterol as compared with the control group. 
The triglycerides level is interconnected with the level of cholesterol. So in the first decade their level in the experiment groups has been $7.1 \%, 14.2 \%$ and $7.1 \%$ higher than the control one. At the end of the experiment the triglycerides level in the $1^{\text {st }}$ and $2^{\text {nd }}$ groups has been $12.9 \%$ and $22.5 \%$ higher than the control and their amount in the $3 \mathrm{~d}$ group has not changed.

During the experiment carotene in blood serum has increased as compared with the control by $11.4 \%, 17.1$ and $20 \%$ correspondingly in the first 10 days and $7.5 \%$ and $5 \%$ correspondingly at the end of the experiment. It is known that carotene combined with vitamin $\mathrm{C}$ causes the decrease of lipoid deposits in vascular walls and cholesterol in blood serum. This tendency has been vividly seen during the experiment time in the $3 \mathrm{~d}$ experiment group.

Taking into account an important role of protein, carbohydrate and lipid components of blood in broiler chickens metabolism processes, the data we have got with birds of the experiment groups after using selenium nano-particles suspension during the experiment time have proved it promotes the increase of storage, productivity and the decrease of fodder consumption.

\subsection{Selenium Nano-Particles Suspension Influence on Productivity}

The chief indexes in industrial poultry breeding are meat productivity and stock livability that make possible to get high profit. During the experiment we have seen a positive tendency in increasing the chickens' live weight when using the study additive. So the weight in the $1^{\text {st }}$ group at the age of 37 days has been $1.8 \%$ higher, in the $2^{\text {nd }}$ group $4.7 \%$ higher and in the $3 \mathrm{~d}-17.3 \%$ higher as compared with the control. It is possible that the suspension of selenium nano-particles has cut the appetite and promoted better food digestion that positively influenced the feed consumption. So there has been $0.15 \%$ cut of feed consumption in the $1^{\text {st }}$ group, $0.80 \%$ cut in the $2^{\text {nd }}$ group and $1.14 \%$ cut in the $3 \mathrm{~d}$ one. The feed consumption per $1 \mathrm{~kg}$ of weight gain has gone down by $1.93 \%$ in the $1^{\text {st }}$ group, by $5.28 \%$ and $15.80 \%$ in the $2^{\text {nd }}$ and $3 \mathrm{~d}$ groups correspondingly as compared with the control.

Table 6. Livestock Indexes of Growing Broiler Chickens

\begin{tabular}{|c|c|c|c|c|}
\hline \multirow[t]{2}{*}{ Indexes } & \multicolumn{4}{|c|}{ Broiler Chickens Groups } \\
\hline & Control & Experiment 1 & Experiment 2 & Experiment 3 \\
\hline Incubation time, days & 37 & 37 & 37 & 37 \\
\hline Preservation, $\%$ & 100 & 100 & 100 & 100 \\
\hline Daily weight, gr & 41 & 41 & 41 & 41 \\
\hline 14 days weight, gr & $353.38 \pm 8.10$ & $355.38 \pm 8.60$ & $352.13 \pm 11.11$ & $355.38 \pm 7.76$ \\
\hline 28 days weight, gr & $1091.25 \pm 46.68$ & $1118.38 \pm 23.06$ & $1238.75 \pm 69.64$ & $1311.88 \pm 46.75$ \\
\hline 37 days weight, gr & $1805.50 \pm 81.38$ & $1837.88 \pm 36.97$ & $1890.50 \pm 111.95$ & $2117.25 \pm 90.56$ \\
\hline Total feed consumption, gr & 44392 & 44329 & 44041 & 43845 \\
\hline $\begin{array}{l}\text { Feed consumption } \\
\text { for } 1 \text { animal, gr }\end{array}$ & 5549.00 & 5541.10 & 5505.10 & 5480.6 \\
\hline $\begin{array}{l}\text { Feed consumption per } 1 \mathrm{~kg} \text { of weight } \\
\text { gain, gr }\end{array}$ & 3074.20 & 3014.90 & 2911.90 & 2588.54 \\
\hline
\end{tabular}

\section{Discussion}

We estimate the physiological state of the organism by the blood. At pathological processes caused by different causative factors the morphological and biochemical composition of blood changes. That is why it is necessary to estimate allenthesis in the organism by hematological exponents. The authors have discovered that additional enrichment of the diet with deficit microelements effect positively hemopoiesis (Mishanin M.Y. 2001, G.A. Nozdrin and others 2009).

From the results of the experiment it follows that the drug in concentration of $0.1 \mathrm{microgr} / \mathrm{kg}$ of live weight has suppressed the generation of erythrocytes, leucocytes and hemoglobin in the organism of broiler chickens. When lowering the concentration of selenium nano-particles suspension the investigated blood exponents have increased by $1-27 \%$ in comparison with the control group. The platelets level has been $40-51 \%$ higher in all the groups in reference to the control depending on the concentration. Other investigations of birds (Nozdrina, G.A. 2009) and horses (Danilevskaya, N. A. 2004) have brought the same results.

Protein metabolism has been active during the whole experiment time. What is more there has been 
accumulation of protein depending on the concentration of the used drug. So in the first decade the crude protein content in the $1^{\text {st }}$ and $2^{\text {nd }}$ groups has been $9.5 \%$ and $37 \%$ higher than that of the control. And in the second decade there has been 4-15\% decrease of the exponent as compared with the control. The albumen level has depended on the period of feeding. So during the first decade it has been 56-100 \% higher than the control. During the second period of the experiment the tendency remained in the $1^{\text {st }}$ and $3 \mathrm{~d}$ groups, whereas albumen in the $2^{\text {nd }}$ group has been $9 \%$ lower than the control.

We have discovered the nano selenium influence on carbohydrates metabolism depending on feeding duration. So the glucose level has been on the average $114 \%$ higher than the control during the first decade. During the second decade the tendency remained in the $2^{\text {nd }}$ group, whereas in the $1^{\text {st }}$ and $3 \mathrm{~d}$ groups this exponent has been on the average $3 \%$ lower. The amylase activity has been high during the whole experiment.

The investigated drug has had positive effect on triglycerides and carotene accumulation in the experiment groups. So the level of neutral fats has been 0-23\% higher than the control and carotene level has been 0-20\% higher. The cholesterol level of broiler chickens has depended on the time of selenium use. So in the first decade its level in the experiment groups has been $8-19 \%$ higher than the control and at the end of the experiment the tendency remained in the $1^{\text {st }}$ and $2^{\text {nd }}$ groups.

Adding selenium to the diet has increased the daily average gain of broiler chickens live weight in all the groups. The difference between the control and experiment groups has been 1-17\%. Herewith there has been 2-16\% decrease of expenses for $1 \mathrm{~kg}$ of gain that is proved by G.A. Nozdrin's data.

\section{Conclusions}

1. The use of selenium nano-particles suspension in the diet has let improve the blood morphological indexes and draw them near the norm.

2. The fodder additive has positively influenced the broiler chickens' growth and development that allows getting larger product yield and reducing expenses connected with its production.

3. The investigated drug lets draw metabolism processes of growing broilers near the norm and improves general physiological state.

4. From the experiments the optimal concentration of nano selenium is $0.001 \mathrm{microgr} / \mathrm{kg}$ of a bird weight.

\section{References}

Barceloux, D. G. (1999). Selenium. J Toxicol Clin Toxicol., 37(2), 145-172. http://dx.doi.org/10.4236/jep.2014.512111

Bogachev, V. N, Kovalenko, L. V., Ivanov, L. I., Folmanis, G. E., \& Volchenkova, V. A. (2008). Suspensions of Nano-Dimensioned Selenium in Crop Growing. Perspective Materials, 2, 54-56.

Danilevskaya, N. V. (2004). Pharma Correction in Perinatal Period at Mares in Foal. N.V. Danilevskaya, T.K. Livanova, M.A. Livanova. Veterinary, 4, 34-40.

Engelman, C. D., Koscik, R. L., Jonaitis, E. M., Okonkwo, O. C., Hermann, B. P., La Rue, A., \& Sager, M. A. (2013). Interaction between two cholesterol metabolism genes influences memory: Findings from the Wisconsin registry for Alzheimer's prevention. Journal of Alzheimers Disease, 36(4), 749-757. http://dx.doi.org/10.3233/JAD-130482

Faure, H., Fayol, V., Galabert all. C., \& Ann Biol Clin. (1999). Carotenoids. Metabolism and physiology, 57(2), 169-183.

Hoffman, D. J. (2002). Role of Selenium Toxicity and Oxidative Stress in Aquatic Birds. Aquat Toxicol., 57(1-2), 11-26. http://dx.doi.org/ 10.1007/s12011-013-9618-7.

Johnson, S. C., Christian, B. T., Okonkwo, O. C., Oh, J. M., Harding, S., Xu, G., Bendlin, B. B., Asthana, S., \& Sager, M. A. (2013). Amyloid burden and neural function in people at risk for Alzheimer's disease. Neurobiology of Aging, 35(3), 576-584. http://dx.doi.org/10.1016/j.neurobiolaging.2013.09.028

Kondrakhin, I. P. (2004). Methods of Veterinary Clinical Laboratory Diagnostics: Guide. Under the editorship of I.P. Kondrakhin - M.: Kolos, 520.

Nozdrin G. A., Ivanova, A. B., Shevchenko, A. I., \& Shevchenko, S. A. (2009). Probiotics and Micronutrients at Quick Rearing of Chickens Cross Smena. Novosibirsk: NSAU, 207.

Peng, D., Zhang, J., Liu, Q., \& Taylor, E. W. (2007). Size Effect of Elemental Selenium Nano-Particles (Nano-Se) at Supranutritional Levels on Selenium Accumulation and Glutathione S-Transferase Activity. $J$ Inorg 
Biochem, 101(10), 1457-1463.

Perunova, E. V. (2000). Physiologic-Biochemical and Productive Exponents of Sows Depending on Doses and Modes of Selenium Administration. Disser. in candidacy for a degree of Candidate of Biological Science. Penza, 141. Retrieved from http://earthpapers.net/preview/53253/d?\#?page=2

Tapiero, H, Townsend, D. M., \& Tew, K. D. (2003). The Antioxidant Role of Selenium and Seleno-Compounds. Biomed Pharmacother, 57(3-4), 134-144. http://dx.doi.org/10.1016/S0753-3322(03)00035-0

Wang, H., Zhang, J., \& Yu, H. (2007). Elemental Selenium at Nano Size Possesses Lower Toxicity without Compromising the Fundamental Effect on Selenoenzymes: Comparison with Selenomethionine in Mice. Free Radic. Biol. Med., 42(10), 1524-1533. http://dx.doi.org/10.1620/tjem.196.71

Mishanin, M. Y. (2001). Physiologic-Biochemical Aspects of Metabolism with Different Levels of Selenium in a Diet of Laying Hens: autoabstract. dis.... Cand. Biol. Science. - Krasnodar, 21.

Motuzko, N. S. (2008). Physiological Indexes of Animals: Guide. N.M. Motuzko, Y.I. Nikitin, V.K. Gusakov Minsk: Tekhnoperspektiva, 95.

\section{Copyrights}

Copyright for this article is retained by the author(s), with first publication rights granted to the journal.

This is an open-access article distributed under the terms and conditions of the Creative Commons Attribution license (http://creativecommons.org/licenses/by/3.0/). 